\title{
Towards an Information Sharing Pedagogy: A Case of Using Facebook in a Large First Year Class
}

\author{
Patient Rambe and Dick Ng'ambi \\ University of Cape Town, Cape Town, South Africa
}

\author{
pjoerambe@gmail.com; Dick.Ngambi@uct.ac.za
}

\begin{abstract}
One of the challenges of using multiple dialogues from a transdisciplinary-informing network of heterogeneous collective of Informers and Clients is appropriating the channel to cognitively shift agents. The role of Facebook as an Informing Network and how both Informers and Clients transform in the process of use has not been exploited. The convergence of agents' cognitive shift and transformative effect during use, paves a way for Information Sharing Pedagogy of heterogeneous informing networks. The paper reports on a study of 850 first year students, over 400 Facebook postings, and employs a Cultural Historical Activity Theory (CHAT) to uncover tensions between the informality and identities of learners in Facebook environments, and the educators' conceptions of academic uses of Facebook. The paper concludes that an Information Sharing Pedagogy of an informing network balances demands for academic networking, protection of identity of agents, and safeguards learning interests and expectations of less confident, academically challenged learners.
\end{abstract}

Keywords: Facebook, Information Sharing, Pedagogy, Activity Theory.

\section{Introduction}

One of the challenges of teaching first year classes is addressing the tensions between educators' teaching strategies and student conceptions of learning. This challenge is compounded when a social networking environment, which is a de facto social interaction space, is used as a teaching and learning environment. In these contexts, it is difficult to recruit student participation without learners feeling that their social space is 'invaded' and becoming uncooperative. The quest to develop an Information Sharing Pedagogy based on learners' social networking environment is, therefore, fraught with challenges of redundant postings, limitations of collective responsibility, subtle negotiations of power between educators and learners, and confusion of roles among novice learners.

Material published as part of this publication, either on-line or in print, is copyrighted by the Informing Science Institute. Permission to make digital or paper copy of part or all of these works for personal or classroom use is granted without fee provided that the copies are not made or distributed for profit or commercial advantage AND that copies 1) bear this notice in full and 2) give the full citation on the first page. It is permissible to abstract these works so long as credit is given. To copy in all other cases or to republish or to post on a server or to redistribute to lists requires specific permission and payment of a fee. Contact HPublisher@InformingScience.orgH to request redistribution permission.
Cohen's (2009) Informing Science framework provides a way of analyzing the role of Facebook in mediating information sharing among students who assume interchanging roles of informers and clients. The need for the informed to also inform is not a typical practice of informing science frameworks, as Birdsall (2009) observes that an Informing Science framework ought to take cognizance of the right of the informed to also 
inform. The use of Facebook among learners reinforces the rights to inform (informer) and be informed (client) and such interaction leads to rich knowledge resources based on multiple voices. However, the freedom that learners experience in Facebook, when exercised in traditional face-to-face classroom sessions where expert (informer) regulation of learning activities is often privileged creates conflicts. Unlike Learning Management System's (LMS) collaborative tools such as discussion boards and chats, which learners often conceive as provided by the institution and open to educator manipulation and regulation, learners usually perceive Facebook as a technology in their control. Normally, students exercise discretion with regard to when and why to open Facebook accounts, make personal decisions on the comprehensiveness of their personal profiles, the personas to project (whether to use real names or quasi-pseudonym), number and diversity of "friends" (personal contacts) to have, and the extent of privacy of their Facebook accounts. Therefore, if not lecturer-controlled, Facebook presents a "student-regulated space" (Rambe, 2009) that augments existing forms of direct lecturer-student interaction and potentially encourages students to voluntarily participate in this space. More so, unlike discussion forums that are usually accessed via the LMS, Facebook is accessed anywhere, anytime by students from their mobile phones.

In social networking, informers and clients interchange roles to create "online knowledge" (Cartelli, Miglio, \& Palma, 2001) based on real life experiences. Real life experience blends both formal and informal knowledge. Cartelli et al. (2001) contend that the new technologies create an intersection of everyday experience and scientific knowledge. Birdsall (2009) observes that clients can either be participants in an informing process or play a pivotal role in the design and development of an informing process. To the extent that users of Facebook engage in information sharing and manipulate the Facebook environment depending on the target audience of messages, they construct the informing process and are informed by it. Cohen (2009) calls for channelfocused research that involves heterogeneity of informing networks in which informers and clients are a collection of agents as opposed to "a single informer and a single client through a single channel" (p.11).

It can be inferred that Social Networking Sites, such as Facebook, facilitate dynamic interchange of roles between informers and clients and blend informal with formal knowledge. Although Facebook is a "tool of action in everyday life" (Rasmussen, 1996, p. 98), the lack of Information Sharing Pedagogy makes knowledge artifacts from multiple users who share everyday experiences difficult to be integrated and used in the classroom. Cohen and Nycz (2006) argue that knowledge from multiple perspectives changes the role of the educator to facilitator of learning. Currently, in Facebook use, learners self-facilitate their learning because they seldom invite their educators as Facebook 'friends.' Viewed as a channel of informing networks, Facebook has the following characteristics:

1. Informers and Clients control the channel of the informing environment (i.e., Facebook) including access to their profiles, postings and inscribers on the Informer/Client individual walls. This suggests that Informers and Clients are involved in the design of an informing process.

2. The Informer may add attachments in the form of documents and/or socialize without any particular agenda. This implies that an Informer's need or task at hand influences decisions of interaction with Facebook and the agency of an Informer need not be explicit. The client engages in a meaning making process and constructs meaning that is influenced by context/environment and the need or task.

3. Facebook interactions and conversations can be backtracked by reviewing the conversation trails. This is particularly important contextual accuracy during the meaning making 
process and serves as a record for the Informer on what was communicated especially if there is need to correlate Client's behavioural change with the messages received.

4. Communicative agents (i.e., Informers and Clients) have a social presence of one another. Resultantly, this online visibility engenders synchronous conversations between communicants, allowing for probing, constructive critique, and challenging of communicants' views. The synchronicity of interchange of roles between Informer and Client leads to a dynamic and heterogeneous informing system.

It can be inferred, from the aforementioned characteristics that first year university learners could benefit from using Facebook. It is envisaged that such pedagogy would be premised on a constructivist paradigm in which the interaction of Informers with Clients, mediated by a Social Networking channel is a process of construction and deconstruction of meaning. During the meaning making activity, both the Informer and Client draw from their social world (social structures), and through the construction and deconstruction process, new understanding is internalized and the agent (i.e., Informer / Client) is transformed as new knowledge is mastered. As Bishop-Russell, Dubord, Hansen, and Webster (2006) reiterate, the regular interactions among Facebook's communicative agents provide users with opportunities for collaboration among people from transdisciplinary backgrounds.

\section{Background}

Rambe and Ng'ambi (2008) suggest that the sharing of electronic resources in Web-enabled environments is becoming an embedded practice among university students. Yet this potential of knowledge transfer is not sufficiently exploited as students often lack the "epistemological access" (Morrow, 1994) to academic conventions that reward those who effectively employ them. Resultantly, previously disadvantaged, working class students' throughput has been problematic for university administrators (McClean, 2004; McMillan 2007, Petersen, Louw, \& Dumont, 2009). The involvement of underprepared students in tertiary education has been accentuated by the South African government Education White Paper 3's (Republic of South Africa, 1997)) emphatic emphasis on equity of access to higher education, and equity with regard to opportunity to succeed within higher education (Hendry, 1998).

A manifold of reasons explain students' general underperformance such as general underpreparedness, student unfamiliarity with the ground rules of university learning, the elite mould of universities that tends to disenfranchise and alienate students from low socio-economic status and culturally deprived home backgrounds which insufficiently support university learning. Notwithstanding these constraints, the Facebook informing process constitutes a knowledge transmission channel through which personal knowledge can be articulated, and academic arguments and social meaning can be collectively negotiated. However, the opportunities to create a shared information pedagogy for effective use of this informing environment is often frustrated by academics' uncertainty about the academic implications of encroaching an uncontrolled, novel learning space. Though as it may, the new theory of Connectivism presents Facebook informing environment as ideal for the generation of networked knowledge from bits of Web based interactional texts. This happens through Facebook's affordances for integration, collation, syndication, and manipulation of content. Reflecting on the profound shift in knowledge generation practices and conventions in contemporary academia, Siemens and Tittenberger (2009) employ Connectivism to explicate how learners connect and collate diverse content and conversation fragments to create an integrated (through sometimes) contradictory network of information: 


\section{Literature Review}

Facebook is a social networking site (SNS) that Mark Zuckerberg, a Harvard university student, developed for university students with contact university e-mail addresses. Although originally designed to allow students to search for peers at universities (Charnigo \& Barnett-Ellis, 2007), Facebook has become a transdisciplinary informing network serving a heterogeneous collectivity of agents in diverse learning contexts. Therefore, Facebook affords students the opportunity to generate their own informal network of friends with whom they share resources (academic and social), friendship connections, and social practices. This has implications for informing science in that an informer is a member of the network and that information sent is received by clients as well those connected to the client. This inter-connectedness of clients and informers constitutes a transdisciplinary social network that mirrors real world networks as people do not just be-friend people from one discipline. Although the social network is interconnected, an informer may focus on a subset of a network as a target to be informed. This creates layers of complexity and barriers to seeking and sharing information (Cohen, 2009) especially in a social networking environment. Cohen (2009) proposes an Informing Science Framework that views informing clients as having needs or tasks, but focusing on needs and/or tasks is insufficient to understand their agency. T. D. Wilson's (1981) model of information seeking behavior provides a way of understanding the layers of complexity and barriers to Informers and Clients in Social Networking contexts. According to this model, information seeking is initiated by informers' psychological, affective, and/or cognitive demands, which embody the meaning encoded in the messages. The informed (i.e., Clients) bring to the process of understanding conveyed meaning their psychological, affective, and cognitive needs, and the negotiations at this personal layer that foster interaction and dynamic interchange of roles between Informer and Client. Both the Informer and the Client have social roles, not limited to ensuring that a positive image of self is projected most of the time, which in turn regulates online behavior. The environment is fundamental in that access to Social Networks requires access to technologies and ubiquity of technologies becomes critical to sustained engagement. Most learners access Facebook from mobile phones and, to the extent that mobile phones are ubiquitous and always available to learners, the Social Network, is virtually available 24/7.

A growing body of literature investigated different aspects of Facebook, ranging from its capacity to foster social integration and informal learning (Madge, Meek, Wellens, \& Hooley, 2009; Selwyn, 2007) and privacy considerations (Boyd, 2007; Grude, Scholl, \& Thompson, 2006), engender social capital formation (Ellison, Steinfield, \& Lampe, 2007), identity management and fostering faculty relations (DiMicco \& Millen, 2007; Hewitt \& Forte, 2006). However, the role of Facebook as an Informing Network and how both Informers and Clients transform in the process of use has not been exploited. In this paper, the Cultural Historical Activity Theory (CHAT) is used to explore the possibilities for pedagogical change and innovation.

\section{Informers and Clients in Facebook}

Unlike Learning Management Systems (LMS) that educators use to distribute resources to learners, registration to Facebook is a learner's decision and the learner tends to have a sense of ownership of a space. The Facebook environment is further reassuring in that 'Clients' are invited by the 'Informer' to become friends. This creates an even balance of power between informers and clients. Some of the challenges of using Facebook as a pedagogical tool are both the educator gaining access to Facebook spaces of all learners and ensuring that every member of the class is a friend of everyone. Although Facebook is not new among learners, the integration of Facebook into the mainstream curriculum and supporting classroom teaching can be difficult. Lack of critical reflection of teaching and learning using technology, unfamiliar teaching and developmental approaches, and the time investment needed to learn how to integrate Information and Communication Technologies (ICTs) effectively into teaching and learning activities are some of the barri- 
ers to Web-enabled teaching and learning in university (McIntyre, 2008; Van der Merwe \& Mouton, 2005). To guard against "technopositivism" (Njenga \& Fourie, 2010), where unsubstantiated emphasis is placed on the technology rather than its pedagogical benefits, critical questions should be posed on how the Web application impacts the teaching and learning of students, particularly those with limited technological skills.

In light of the aforementioned pedagogical challenges that accompany the implementation of Web-enabled courses, this study investigates the impact of Facebook use on three Information Technology (IT) educators' teaching strategies and their students' learning experiences. Using Cultural Historical Activity Theory's (CHAT)'s five principles of activity systems, multivoicedness, historicity, contradictions, and transformative learning, the study examines the challenges these educators experienced in teaching a blended Information Technology (IT) course and how these challenges and dilemmas catalysed pedagogical innovation and change in students' learning practices. While a handful of studies have employed Engeström's (1999) five principles as a fundamental analytical framework (Carr, Morrison, Cox, \& Deacon, 2007; Engeström, 2001; Murphy \& Rodriguez-Manzanares, 2008), they did not examine social networking environments as an Informing System in a blended learning course.

Using a blended learning course (combined face-to-face lectures with a Facebook environment) as a case study, a multi-method framework that corroborated data from Facebook postings, post observation de-briefings with educators, and in-depth semi-structured interviews with students and educators was employed to unpack the influence of Facebook on educators' teaching and undergraduate students' learning. These constructivist learning environments are worthy of study as they take advantage of emerging technologies to immerse students within contexts that challenge, ground, and ultimately, extend their understandings (Barab, Barnett, Yamagata-Lynch, Squire, \& Keating, 2002).

The peculiarity of Facebook was derived from the fact that (1) student consultation was deemed not necessarily educator-dependent (students could inform and be informed by peers and senior students in addition to the online administrator), (2) informing process was not time-dependent (students could inform and be informed anytime, anywhere, during official working hours), and (3) Facebook created a quasi-formal information-sharing environment (information was not limited to scholarly issues) (Rambe, 2009). As such, the educators' expectation was to foster a knowledge-sharing environment that was not educator directed.

\section{Cultural Historical Activity Theory (CHAT)}

An established account on CHAT is known to have emerged from the works of German and Russian psychologists in the $20^{\text {th }}$ century, particularly the luminal works of Levy Vygotsky, Luria, and colleagues. Levy Vygotsky's (1978) formulation of the genetic general law of development, which acknowledges the collective nature of human consciousness manifested through social interaction, laid the foundation of CHAT. If learning is constructed as a socially mediated activity that unfolds through Informers' use of semiotic and cultural tools (language, textual messages) to support Clients' internalisation of new knowledge and new ways of understanding, then there is scope to suggest that Facebook presents an ideal informing network/ system, which potentially triggers cognitive shifts and transformative learning processes.

CHAT requires, at minimum, a shared understanding of the character and history of the subject, the object into which the subject is attempting to reach, and the characteristics of the surrounding community and the tools available to the subject (Koszalka, 2002). At the centre of CHAT is the understanding that activity is an objective oriented, culturally mediated process that unfolds through the process human interaction at multiple levels, individually, collectively in groups and as communities to achieve certain conscious motives and intentions. The object-oriented nature of 
human cognition and activity is apparent in Leontiev's (1978) theorisation of an object of activity: "The object of an activity is its true motive. It is understood that the motive may be either material or ideal, either present in perception or existing only in the imagination or in thought" (p. 62). This conception of objects implies that without a clear motive, the activities of different Clients and Informers and the associated actions among them would be random, unsystematic, and void, if not directed by certain motives. As such, without examining the cultural-historical construction and content of objects, our understanding of activity and cognition remains formal and superficial (Engeström, 1995).

The use of CHAT is consistent with Cohen's (2009) call for research that explicates the cognitive and physiological elements of informing. Our thesis is that semiotic tools (such as language of both the Informer and Clients) and cultural artefacts (the informing channel, for example, Facebook) constitute the material through which communicative agents (i.e., Informer and Clients) draw on, deconstruct, and make sense of their social world. As such, CHAT offers a more realistic, analytical framework for an examination of the relationships between the Informer, channel, Client, and the context. CHAT was developed to overcome the dualistic body-mind and individual-culture splits characteristic of many approaches within psychology and sociology (Roth \& Lee, 2004). To the extent that CHAT values social interaction of human agents, CHAT serves as a critical tool for examining Informing Networks in situated contexts and associated contradictions.

Contradictions in activity systems force subjects to develop a new orientation towards the object and manifest in disturbances that trigger shifts in established work practices. Our use of contradictions as an analytical tool differs in function from Engeström's change laboratory orientation. We use contradictions to analyse tensions between different activity elements of Informers and Clients as impetuses to account for "human fragilities" (Cohen, 2009, p. 8) and changes in the use of an Informing System rather than assume a narrow focus on need (or task) as driver.

Although some of the studies using Activity Theory as an investigative and analytical tool describe technology as an Informing System (Barab et al., 2002; Engeström, 2000; Russell \& Schneiderheinze, 2005), they are not rooted in higher educational contexts (Engeström, 2000; Russell \& Schneiderheinze, 2005) and do not focus on the pedagogical complexity of Informing Networks in transdisciplinary contexts. Thus, in this paper, the analytical framework serves the following functions. (1) To track and monitor learners interchanging roles of Informer/Client in Facebook interaction as a basis to infer their learning trajectory and development changes. (2) To examine how the development changes in function 1 impacts on changes in educators' informing strategies. (3) To explore how lessons from functions 1 and 2 can be harnessed to develop an information sharing pedagogy.

\section{Engeström's (1999, 2001) Principles of Activity System}

An activity system comprises the individual practitioner (informer/client), the colleagues (other informers or peers) and co-workers of the workplace community (community members), the conceptual and practical tools, and the shared objects as a unified dynamic whole, and, therefore, cognition and expertise are products of artifact-mediated, socially distributed activity (Engeström, 1992). In the Facebook learning environment, the informing process is a dialectic, dynamic process where both the Informer and Clients employ cultural artefacts (textual messages, iconic features) to engage in cognitive transformation processes and expertise development processes activated by transaction and exchange of roles (division of labour). In summary, Engeström (1999) proposes that the Activity theory can be analytically summarized by five principles namely, activity system, multivoicedness, historicity, critical role of contradictions, and expansive transformations /learning. Because these will inform our investigative framework, we will unpack the anatomy of each of them with a view to set the stage for the detailed discussion for our findings. 


\section{The activity system}

The first principle is "a collective, artefact-mediated and object-oriented activity system, seen in its network relations to other activity systems, is taken as the prime unit of analysis" (Engeström, 2001, p. 136). The central thesis in Engeström's work is that activities and activity systems are goal directed processes of informing and knowledge acquisition that unfold through cultural artefacts (culturally-mediated tools) and socially enacted exchanges and interdependencies. This implies that a complex hierarchy of heterogeneous relations and interactions emerge in the Facebook informing networks at personal /dyad (informer-informer, informer-client, client-client), tool-in-use and object levels, meso (group level), and the entire activity (academic community) levels. As Zurita and Nussbaum (2007) contend, activity, or "what people do", is reflected through people's actions as they interact with their environment, studying different forms of human praxis as developmental processes, both individual and social levels interlinked while at the same time providing an alternative way of viewing human thinking and activity. As such, activities may conceptually and technically not be grasped out of the context in which they unfold and co-evolve as the context provides that material form and ideological scope by which subtly nuanced activities are given effect and credibility.

\section{Multi-voicedness}

The second principle is multi-voicedness and Engeström (1992) argues that expertise is attained through continuous processes of dialogicality and multi-voicedness between experts and novices. For him, this implies that the acquisition of expertise in any given field is an ongoing dialogue or polyphony of multiple competing and complementary viewpoints and their respective "instrumentalities", repertoires of mediational means, which is a resource for collective achievement and a potential source of fragmentation and conflict. In an informing network/system like Facebook, a process of cognitive scaffolding and apprenticeship emerges as Informers (educators, knowledgeable peers) and clients (students) share knowledge through dialogicality and multiple, competing and mutually reinforcing voices. This informing process between the Informers and Clients, clients and clients (knowledgeable peer who can also be an information seeker at other times), and information seeking peers catalyses changes in the way these informing agents behave and enacts transaction of social practices.

We propose that different voices from Clients and Informers are instantiations of their different positioning and agency as shaped by their own socio-historical contexts, their epistemic frames, ideological dispositions, and training backgrounds. The introduction of an informing social network like Facebook presents a communication channel through which different objects of activity can be sought based on the Clients and Informers' heterogeneous schooling/learning histories apartheid legacy, experiences of advantage/ disadvantage which potentially activates/subverts negotiation of agency and the realisation of consciously intended objects.

The hierarchical structure of an activity system is permeated by its multi-voicedness character as participants in their different positions go along with their narratives carrying its history engraved in the mediating artefacts and rules (Matos \& dos Santos, 2008). We interpret that socio-cultural and historical circumstances in which the interaction evolves shapes not only the diverse positioning of Clients and Informers in the informing process but rather encodes certain interactional genres, ground rules of behaviour/social conduct, and agency as afforded and /restrained by the toolsin-use. Our understanding of interactional history is convoluted - comprising spatial dimensions of the interactions (as in-class activity, or lab activity), temporal dimensions (episodes in an activity), and historical (as defined by previous interactional history). Given this nuanced conception of context, it's plausible for multi-voicedness to unfold at either or all these levels. The reasoning behind multi-voicedness is an abstraction of Bakhtin's (1986) concept of heteroglosssia, which 
explains one's utterance, not as an exclusive expression of the speaker's intentions and voice, but rather a hybrid complex populated by other people's intentions, perceptions, and voices.

\section{Historicity}

Historicity emerges as Engeström's (1999) third principle, and this underlies the consideration of the history of the social agents in the interactional context, the history of the tools-in-use, and that of the interactional rules and division of labour. Engeström (2001) reasons that the molding and transformation of activity systems take a long time and, therefore, history needs to be grasped as local history of the activity and its objects, and as history of the theoretical ideas and tools that have shaped the activity. Human interaction is also shaped by the cultural artefacts that structure human agency and identity what Bernstein (2000) described as "habitus." He articulates that:

Whilst it [habitus] may solve certain epistemological problems of agency and structure, it is only known or recognised by its apparent outcomes. Habitus is described in terms of what it gives rise to, and brings, or does not bring about... But it is not described with reference to the particular ordering principles or strategies, which give rise to the formation of a particular habitus (p. 133).

In an informing system, habitus is exemplified by the outcomes of the objects of the activity (for example, mastery of IT theories and concepts, proficiency in IT technical processes) rather than by its motivations. This construction of habitus invokes the conception of Clients and Informers' diverse mental dispositions and positioning as products of immediate interactional context and interdependencies afforded by the interaction, as well as culturally encoded material that control agents' psychological functioning. Yet the habitus of Clients and Informers complicate the comprehension of activity and activity systems because, in our view, it is activated at different levels during the interaction - in the Client's agency and choice of the Client/Informant to interact with, in the process of deconstruction of messages by agents (Informers and knowledgeable Clients), and in inferences made and the responses constructed. This is because habitus is intricately embedded in historicity, which shapes the identities and mental frames of the agents in communicative events.

\section{Contradictions}

Engeström conceives transformation and change to happen through the intervention of change laboratory. Unsurprisingly, his characterisation of contradictions carries a strong working environment orientation. As Hasu and Engeström (2000, p. 65) suggest:

Contradictions manifest themselves in disturbances and breakdowns in work processes as well as in workers' innovative attempts to solve them. The notion of breakdown has been used to refer to a disruption in the normal functioning of things forcing the individual to adopt a more reflective or deliberative stance toward ongoing activity [...] Disturbances are analysed as deviations from this scripted procedure.

Uden and Kumaresan (2007) suggest that Engeström's (1999) analysis of contradictions underlies the process of social transformation and incorporates the structure of the social world, with particular emphasis upon the conflictual nature of social practice. We infer that contradictions trigger change in conception of the object, in the social behaviours that underpin agents' (Informers and Clients) social practices, and in the reconfiguration of the elements of activity and between activity systems (the informing environment). Agents' ways of being and knowledge systems are transformed in an informing environment as contradictions emerge through their process of interaction or conceptualization of the object. 


\section{Expansive learning}

Expansive learning in professional settings unfold through, in Daniels' (n.d.) terms, learning of professionals in the creation of new forms of practice which require joint solutions to meet complex and diverse client needs. For Engeström (2001) contradictions in activity and activity systems trigger transformative learning and this happens through critical questioning of existing practices and deviations from the script (normal practices) as new understandings emerge. An expansive transformation is accomplished when the object and motive of the activity are reconceptualised to embrace a radically wider horizon of possibilities than in the previous mode of the activity (Engeström, 2001). Expansive learning entails students building their own scaffolding and resources for learning, through which they may generate reflective understanding of their own practices and conceptualisations, not only for themselves individually, but as a collaborative group (Morrison, 2004).

\section{Methodology}

This study employed an ethnographic case study approach. The TESOL Quarterly ("Qualitative Research," n.d.) presents ethnography as a complex theoretical orientation toward culture - in collectives of differing magnitude, whether educational institutions, student communities, classrooms, or activity groups. The same Quarterly acknowledges culture as heterogeneous, conflictual, negotiated, and evolving and sees descriptions of culture as shaped by the interests of the researcher, the sponsors of the project, the audience, and the dominant communities. Our goal was not to establish the culture of university learning per se, but to unravel the experiences and pedagogical implications of a networked community (educators, students) interacting in a blended learning course.

Mindful of our goal to unpack how Facebook uses impacted pedagogical strategy and student learning in authentic learning contexts, we are convinced that a holistic understanding of the realities of pedagogical practice in such contexts would necessitate an ethnographic approach. This perspective demands our understanding of the process of data construction and its analysis as a joint enterprise between Clients, Informers, and the researchers. That is, the data collection, analysis, and interpretation involve a recursive, progressive, and yet dialogic exchange of information and ideas among Informers (educators, knowledgeable students), clients (novice students), and the researcher in situated contexts.

The study was conducted on three first year educators in the Commerce Faculty at the University of Cape Town. This elementary course had several topics taught by different lecturers at different phases/times of the semester and in succession. For logistical purposes, the learners were divided into three clusters to form three classes/courses. The first course, CLASS1002H (not its real name), comprised about 50 students with limited/ no prior ICT skills and some had English language problems. The second course, CLASS1002F, comprised 800 students with sophisticated ICT skills and was split into two clusters. The methodological choice of Commerce students was informed by the fact that this was the only academic stream in the university that encouraged use of Facebook as a teaching strategy.

The three clusters covered the same course material although the CLASS1002F finished the course in the first semester given their prior exposure to ICTs. The CLASS1002H cluster was on an extended curriculum programme for a year. To ensure that trends and shifts in teaching practices were tracked and documented, the three clusters were observed for the duration of their courses, that is, one semester (for 4 months) for CLASS1002F and two semesters ( 8 months) for CLASS1002H. In total, 15 in-class observations were conducted over this duration. Each observation lasted 45 minutes, the duration of a lecture session. 
An educator (Informer) who taught all three clusters created a Commerce group on Facebook and students (clients, potential informers) were required to create Facebook accounts (informing channel), and to join the group. This Facebook group comprised one cluster/group for all first year students doing this ICT course. A course convener (another informer) maintained a social presence on the Facebook group and offered limited administrative support to students upon request. The educator, however, assumed the online course instructor's role of addressing academic queries and questions students asked during the normal working hours $(8 \mathrm{~h} 00$ - 16h30). Notwithstanding the differential levels of prior exposure to ICTs in high school, all students interacted on the same Facebook site. Students consulted with the educator on theory, practical, and course administration issues. They had three options on Facebook for consulting with an online administrator and with peers: the administrator's inbox, discussion board, and the wall.

There were 165 Facebook participants representing 20\% of learners (850 first year students were investigated). A total of 414 messages were posted; 154 wall posts, 121 discussion board posts, and 139 posts to the administrator's inbox. Of the 165 Facebook participants, 46 were interviewed (14 students from CLASS1002H and 32 from CLASS1002F) in addition to three educators. Interviews focused on experiences on the use of Facebook as an Informing Network with particular reference to tensions between activity elements of Informers and Clients and their human fragilities. Of the three educators interviewed, two interacted with learners on Facebook.

\section{Analysis of Results}

In Activity Theory, there are different representations of unit of analysis in activity systems. As the Laboratory of Comparative Human Cognition (in press) suggests, two strands of thought have emerged in relation to the unit of analysis in Activity Theory. On one hand, there are constructions following Vygotsky's work, which emphasise artifact mediated action in situated contexts as the central unit of analysis (Vygotsky, 1978; Wertsch, del Rio, \& Alvarez, 1995). To the contrary, other scholars who draw on the work of Leontiev give prominence to the human activity (as individual or in groups) as the main unit of analysis (Engeström, 1987, Kaptelinin, 1996). We contend that these differences are not fundamental but are variations of emphasis rather than structural divergences. It seems the central point is that different studies emphasise different units of analysis depending on their ideological premises, main research questions, and rationale of these studies. Mindful of the course as an expression of an activity, we adopt the course as the main unit of analysis. Our choice is explained in the section below.

\section{The Activity System as the Unit of Analysis}

For Barab, Hay, and Yamagata-Lynch (2001, p. 69), an activity system can be an entire course, a particular class, or even an isolated event. For this study, the entire course, which involved technology mediated interaction (Facebook) was adopted as the unit of analysis. The choice of the course as a unit of analysis emerged from the understanding that Activity Theory strives to develop a holistic and multi-layered understanding of the interaction between human subjects (informers and clients), mediating artefacts, objects of activity, rules of engagement, roles of the community with which participating subjects interact with (collectively conceived as the informing process), and the tensions that emerge from these interactional processes. The course level, therefore, provides a vantage point from which to interrogate the activity system in its entirety, that is, course goals, objects of artifact-mediated interaction, different gender roles and perspectives of participating subjects (informers and clients), and the influences of socio- historical conditions on interaction. The course level analysis also allows for easy abstraction from the macro level issues relating to the course to the micro level issues of individual learners. 


\section{Social Presence in Artifact Mediated Interaction}

Engeström (2001) formulates the activity system as the central focal point in the examination of individual behaviour and actions. As such, activity systems constitute collective, artefacts mediated processes that involve human actions and operations aimed at achieving pre-determined goals. We interpreted academics' goal of introducing Facebook as creating a shared educational, communicative and informing space for developing understanding of theoretical and practical issues in a specific discipline. Facebook also served as an interactional space for negotiation of meaning of academic concepts and academic networking. In a detailed face-to-face interview, one Informer, namely the CLASS1002 course convenor, chronicled the vision of the academic use of a social networked space, Facebook:

The first purpose was to get students to understand what the course is about by using the system (Facebook). They also use it to share academic information, examples and study issues, and also to contact and question the educators. Theron ${ }^{1}$ [an educator] runs the Facebook site from the academic side, and she interacts with the students through facebook. They ask questions to the educators/ academics and those are generally questions about process, aspects of the course. We are hoping they are going to start discussion threads as well. (Interview with course convenor)

We infer that three motivations stimulated the academic engagement on Facebook, namely, the operationalisation and verbalization of experiential learning of IT using an instance of an information system (Facebook), the construction of networked knowledge through the sharing of IT examples and inter-client interdependencies, and the generation of pedagogical knowledge through client's (student) critical questioning of the informers (the educator, knowledgeable peers).

While Informers (educators) rationalised all inter-client exchanges and informer-client interactions (i.e., questions, queries, clarifications, elaborations) to be informed by the aforementioned goals, clients' motivations for Facebook use were manifold and invariably not aligned to informers' intentions and motives. We recognised student inclinations that were ancillary to the main object of an Information Sharing Pedagogy conceived by educators. Clients (students) echoed perceivably flippant considerations like pragmatic functionality of the informing system (quick communication, instances of synchronicity), visibility of online participants (social presence of peers or informers) and possibility for self expression in a "safe and user-friendly space. As one student revealed in an interview:

The Facebook application allows me to check who is online so I can link up with my classmates instantly. The Facebook chats especially on social issues, but sometimes on course content, are an instant two-way communication. This is compared to Dynamic Frequently Asked Questions (DFAQ ${ }^{2}$ ) where interaction is asynchronous. On Facebook, if my peers/educator is online, they can respond instantly to queries. As for DFAQ, although I get the message it can be a delayed response. (Student Interview)

The student's account above conjures the perception that while educators implicitly anticipated academic engagement through artifact mediated interaction (textual messages, queries, and questions), student presence on Facebook proved not exclusively scholarly. They used the space to socialise with peers and for whiling time, in addition to inquiring about academic matters. Another inference is the inversion of the authority to inform as the onus of knowledge generation and information seeking was not necessarily the exclusive preserve of the informer (educator) as

\footnotetext{
${ }^{1}$ All the names given in this study are pseudonyms

${ }^{2}$ An anonymous consultation environment designed and developed at the University of Cape Town by one of the authors. For details see: http://onlinelibrary.wiley.com/doi/10.1111/j.1467-8535.2008.00899.x/pdf
} 
the informing network expanded. The desire for instant communication is invoked with reference to the synchronicity of Facebook communication and this desire cannot be interpreted as consonant with academic engagement.

\section{Affective Presence in Communication Tool}

The academic conception of Facebook interaction was deeply implicated in other affective and emotional affordances of this informing channel. The reciprocal and recursive interactional process in this heterogeneous knowledge system was connected to the sentimental and symbolic value some clients (students) attached to the space and, perhaps, not to its academic significance. One student stipulated Facebook' impactful, personal dimension this way:

The personal side of Facebook communication is that when my peer types, it even indicates that James [pseudonym] is typing so I know the person is responding. Facebook has different colours to show participants online, busy or offline allowing me to handle the person on the other side accordingly. Unlike e-mails, the Facebook's photo application polishes communication as I am persistently reminded of my peer during interaction thus bringing proximity. (Student debriefing)

Facebook is distinguished from e-mail for its sense of intimacy as well as a multi-layered communication it bestows. The photo is given as one sublime form of communication medium (first layer) and the message as a complement medium (another layer). The learners' presence on Facebook, though academically inspiring, needed evaluation against the goals of effective participation to ensure that her activities and roles on it gainfully supported academic networking.

\section{Computer Mediated Communication - A Buffer Zone for Shy Students}

The computer mediated nature of the tool (Facebook), its quasi-informal ambience, and the pseudonymous aura/impression it presented collectively bolstered shy students' confidence to seek information from the educator on academic matters, which was occasionally frustrated in class. This could be compared to huge lectures where these students often felt intimidated to ask conceivably unsophisticated questions for fear of ridicule by peers or because the class size constrained direct questioning behaviour. One less confident introvert recounted:

Facebook is an ideal learning space for shy students like me as I do not have to worry about other students knowing that I asked that question. I might feel that the question is weird or maybe other people already know the answer, and they will ask where I was when that issue was taught in class. Why didn't I ask in class or how come I don't understand? So the mysterious ingredient of it [anonymity] is what I like as it protects me in my questioning. (Student debriefing)

The unintended consequence of Facebook was that it modeled and accentuated timid students' information seeking behaviour as they were anonymous (in Facebook in-box communication) or thought they were (in Facebook public space). Clients (students) were allowed to experiment with practices of critical academic inquiry through critical questioning and recruitment of feedback from Informers. Expounding the virtues of computer mediated communication, another previously disadvantaged student echoed similar sentiments in a separate interview:

I noticed that when you are not face-to-face with an educator, there is more freedom of expression, a potential advantage of Facebook. The secretiveness allows me to communicate or ask questions that I would not otherwise communicate the same way face-to-face. It gives me a certain kind of liberty to talk because after all, I am not seeing them and 
they are not seeing me. This is nice especially if I don't want people to know that it is me sending it. (Student, interview)

The preference for private communication, while logical for students (subjects of activity), was problematic for academics driven by networked knowledge production as it violated the principle of public contribution to knowledge for peers' benefit (that is, through public spaces). Therefore, while the aforementioned presents evidence for clients' preferred channel of information seeking and knowledge generation, the lack of Information Sharing Pedagogy complicated the effective use of knowledge artifacts from multiple users and drawing on this information in class contact.

\section{Heterogeneous Dialogicality}

Educators' object of appropriating Facebook was informed by the multiplier effect of networked interaction. Uncooperative students' discernment of their peers' academic engagement was deemed to vicariously spur their voluntary involvement. The networked effect of Facebook interaction is implied in the educator's view that:

Our teaching has been eased by Facebook because with so many students, if you had to deal with all of them one-on-one, it could take long. So we refer to Facebook and say that question has been answered on Facebook. For academics, Facebook is an open, easy and quick channel of communication with all students. The most important benefit however, is that students can network amongst each other, as students provide responses on content and source to peers. (Educator interview)

There is an aura of automatic conformist behaviour implied by the view that students would network among themselves. It was envisaged that the benefits of academic networking would spill over to all peers thus generating a compact networked community. In practice, the limited peerbased networking suggests that academics had not sufficiently rationalised a pedagogical strategy on networked learning.

Although educators built Facebook consultation around the philosophy of peer-based collaboration, students held heterogeneous, inherently conflictual notions of the incentives of networked interaction. This view is demonstrated in the student articulation below:

The problem with Facebook is that anybody can just access your personal information, and if you are not careful, this potentially invades your comfort zone. Many of us joined Facebook without really knowing what it was only to realise that it is too exposing - my friend or my ex-girl friend is doing this, something morally wrong. Someone can also spy on me using Facebook and they might be people whom I am really uncomfortable accessing my personal information. (Student interview)

Facebook reportedly violates personal privacy considerations, and some students were sceptical about academic participation as they were wary of their personal lives and "comfort zones" being invaded. The anxiety of perceived academic surveillance and subversion of private life has implications for academic integration of this social networking space. The concerns about privacy seemed to supersede the academic worthiness of the space for unsophisticated students, who perceived this space as a potential threat to personal freedom and social existence.

Notwithstanding the above concerns, Facebook was one of the central places of academic networking:

I use Facebook in Information Technology to inquire from my online administrator about assignment tasks, like developing a literature review. I send questions through the Facebook group and I also read questions that my classmates asked and the responses they got. It's not always about research, at times it is about knowing how other people are 
thinking, and questioning oneself whether I am also thinking in that direction and getting the information. (Student interview)

Critical inquiry, information seeking behaviour, and mental modeling are all embodied in the above account. Some Clients used Facebook for asking questions, recruiting answers, and to track the psychological dispositions of peers in order to model their personal behaviour appropriately.

\section{Gender Performativity}

Judith Butler, a post-structuralist feminist philosopher, coined the term gender performativity in her 1990 book, Gender Trouble. She characterises gender as the effect of reiterated acting, one that produces the effect of a static or normal gender while obscuring the contradiction and instability of any single person's gender act ("Gender performativity," n.d.). In our case, some students employed Facebook to act out their masculinity and associated gender roles in this public space where their peers served as watching audiences.

Other students were more concerned about the use of Facebook as a platform for self-expression on social matters rather than deliberations of academic discourses. The arbitrariness and the less explicit nature of this networked space rendered it an ambivalent educational and ideological space, one that could be hijacked for impressionist motives and egocentric attitudes. The absence of specific academic tasks in-built into the technical architecture of Facebook posed challenges of the capacity of the space to recruit and focus academic behaviour among participants and elimination of off-the-task behaviour. Exploiting this loophole in the technical configuration of the informing network, some male students paraded their chauvinist disposition to a watching online audience.

Wall Post 134. Kopano Boys are in this room again again... You guys probably know the rest by now! Kopano Yeah!!! Anyone know what da F1 button does again?

The male student deliberates on the activities that male students in one of the university's male residences do. The presentation of this social message further complicates Facebook's capacity to nurture academic networking if student objects on Facebook are not aligned with academic motives. The strong social inclination of Facebook is apparent in another student's explication that the self-control it affords serves as a potential detraction for learning:

Facebook promote self-fashioning because you can construct a whole persona around it. When online, its aspects of my personality that I wish to project and perpetuate which could be part of the broader identity of who I am. There is a self regulating psyche behind it and I am on the drivers' seat with my profile and there is an audience watching, and that this thrilling for me. (Student Interview)

Facebook, therefore, presents a platform for the articulation of self identities which, if maligned with scholastic intents, could lead to goal displacement in academia. While social networking serves as a nascent expression of an academic community, it is critical inquiry among informers and clients through the informing channel that triggers higher psychological functioning and transformative learning processes.

\section{Subtle Historical Influences}

In development and learning, a sociocultural context influences the ensemble's (e.g., dyad, triad, or group of any size) choice of activities and endows them with meaning (Granott, 2005). The 
context, as we have already argued, is not exclusively the immediate socio-cultural context in which communicative agents (Informers and Clients) find themselves, but rather encapsulates, in Engeström's (2001) words, "local history of the activity and its objects, and as history of the theoretical ideas and tools that have shaped the activity" (p. 136-137). This implies that different immediate social contexts (information needs of Clients, desire to socialize and exchange views, limited facial contact with Informers in class) and historical circumstances activate Clients' (student) engagements on social networking sites. Given South Africa's history of apartheid that has subtly associated academic potential with race and social status (through varied prior access to ICTs, different educational resources in the home, parent academic, financial and moral support), student use of Facebook has been motivated and sustained by different social and historical circumstances. One student portrayed her appropriation of this informing process as driven by the negative stereotypes and notions about previously disadvantaged races being less intelligent and, hence, limiting her academic participation in class:

There is the view that students of colour are have a lower IQ [intelligent quotient] and are not wise and this makes me inferior. I find it hard to participate in class because I am not sure whether I will not ask a ridiculous question, which will make me mocked by the class. That is why I prefer posting my queries on Facebook to asking in class. (Student debriefing)

The student presents negative stereotypes of previously disadvantaged races, possibly formed during Apartheid legacy, as explaining her general apathy in class. Her peer, from a previous disadvantaged background, also echoed a similar response in a separate interview:

I do not normally ask questions in class. I am very shy [...]. I would rather post my educator a message on Facebook inbox than go to see her. You know when I ask a stupid question I don't want to see on her face that she is saying, "It is a silly question!"[...]. She should just answer that. If it is silly fine, but she should answer it. (Student interview)

The above raises pertinent questions about the pedagogical use of Facebook that would allow academics to eliminate and transcend the sense of alienation and academic powerlessness that pervade unprepared students. There is a danger that these feeling of marginalization and alienation could be replicated online (just as they do in face-to-face contact) if the Facebook informing system does not tackle these negative stereotypes.

Historical disadvantages also explained the technophobia that limited some underprepared students' non-involvement on Facebook. A learner bemoaned that:

I only started using computers in my first year at university. Actually my sister opened a Yahoo account for me and taught me how to type assignments. I am also technophobic and I haven't tried Facebook as I am intimidated to try out new technologies. I tend to stick to the basics like Microsoft Word and PowerPoint and my peers laugh at me, but I don't care-so long as I know the basics. (Student interview)

The limited access to and use of technologies during this learners' high school seemed to account for her attitude towards technology and this possibly molded her future behaviour in the informing environment. This can be contrasted to her male counterpart from a fairly sophisticated middle class background who suggested that:

I come from an elite background, we had a computer and Internet access at home and my parents always emphasised that I should just read books... When I get on Facebook that threat is already within me, so the first thing that I look for on facebook is academic material. (Student interview) 


\section{Contradictions as Forces for Change}

Tensions existed between the informality of Facebook identities in Facebook environment and the educators' conceptions of academic uses of Facebook. Informers (subject of activity) conceived in Facebook a space for the client articulation of their academic queries, exchange of academic knowledge, and mastering the notions of academic networking. Students (as community members) did not always share this grand vision but, rather, were bound to self-initiate and self pace their Facebook activities and were wary or sceptical about the possibilities of Informers co-opting their informal channel. The narrative below manifests student ambivalence and resentment of educators' presence on Facebook:

Facebook is a personal thing, you have got your profile, your photos, and friends writing on your wall. If you don't want to let your educators see your profile, you can hide it because it's none of their business. I don't see why Professors should trespass into our own environment. I would be worried if they start sending me invitations to befriend them, because I have known them as my mentors not colleagues. (Student interview)

The above is indicative of the tensions that emerged between clients' (students') conception of learning and informer's pedagogical strategy. Some learners who had already appropriated Facebook for social networking long before educators presented it as a teaching and learning space were often sceptical and critical of what they conceived as a encroachment of their rendezvous by the academic nobility. There is a self-controlling psyche behind Facebook that affords both the Informer and Client some control over the channel of communication and how the communication itself actually unfolds. Unlike Learning Management Systems that are build on the industries' philosophy of the four Gs-where the Informer generates, gathers, groups, and gives information (Miller, 2000) to Clients, on Facebook clients (students) like experts (informers) exercised control on the information generation, aggregation process and its delivery process.

\section{Role Confusion and Subtlety of Interaction}

Students were often confused about what role they would perform on Facebook and the implications of incorporating educators in their informing framework on Facebook. This is apparent in this student's reflection:

The issue [with regard accepting an educator as a facebook friend] I want to ask you is when you add your educator as a friend does it mean you are friends or does it open a channel of communication for you? What is their role and how do they complement that of our peers? If I get an invite from my educator so that we could communicate to reduce the effect of distance, to reduce my academic problems, or to discuss something online, then I probably would accept their invitation. But if there is any other agenda beyond that I wouldn't accept because I am not used to having a close relationship with educators. (Student interview)

While academics' invitation to students to engage on Facebook conveyed the capacity of the space to create a transdisciplinary convergence zone for clients and informers, particularly if academics from related disciplines were recruited, students expressed ambivalence about the implications of this interconnectedness. The dilemma laid in understanding the role of the educator in an informal learning environment, the academic implications of bringing professional experts in a quasi-formal environment, and the risk of their academic potential and real life conduct being judged by educators on the basis of their playful behaviour on Facebook.

As one student, when probed on why he objected to sending an invitation to his educator yet he would consent to his educator's invitation to befriend him, quipped: 
It would look awkward for me to invite them unless if we were friends in real life. Maybe we understand technology differently but I don't look at Facebook as an academic tool but rather a social communicative tool. I know there have been some arising issues associated with Facebook like people sending pornographic materials that has an impact on the way academics perceive Facebook and its importance for learning. (Student interview)

The student was hesitant to accept his educators as friends notwithstanding educators' public announcement in class that Facebook could be employed as an academic networking space. It stands to reason that a deeper conceptualisation of the multiple layers of complexity of InformerClient interactions on Facebook is critical to the effective integration of this transdisciplinary informing network with the mainstream curricula. Educators were forced to reiterate their instructor and advisory roles and the benefit of Facebook interactions each time they lectured students. This served to demonstrate that the often taken-for-granted assumptions about educator-student relations had mutually adjusted and reaffirmed to give effect to meaningful pedagogical support and transformative learning. The shift in teaching practices was from implicit networked relations to explicit reinforcement of pedagogical goals.

\section{Expansive Learning}

Expansive learning involves student engagement in transformative learning processes that trigger changes in their ways of reasoning. These learning processes manifest in the change in social practices, new conceptions of the object and shifts in the division of labour (roles) to accommodate the dynamic changes in the activity systems. The heterogeneity of the Facebook informing framework allows Clients to be participants in an informing process and to play a pivotal role in the design and development of an informing process. The synchronised communication and informing process Facebook presents created a dynamic consultative process involving multiple, and often heterogeneous, voices as some knowledgeable students assumed new vertical roles of advising peers and giving direction on task execution. A typical example of this consultative process on theoretical matters involved a knowledgeable Client informing a Client (novice) on the Facebook wall:

Wall Post 37. Hi Theron [pseudonym]... Just a little confused. Are we supposed to be able to link our site to an actual database? As well as in the search function? Or is it sufficient to just have a page to show that we did think of it? Thank you

The inquirer (Client) requests from the knowledgeable student how to develop and link the database. The Informer renders an intelligible response:

Wall Post 36. You cant get the Database connection fully functional to test. This is because we need to have the site published and Database on ASP enabled server. So i think the latter option would be sufficient. The search thing you can get working without the connection to the Database. I used a program called Zoom Search engine

The students suggest a software program to the inquirer and the processes of having the database functioning which the Facebook administrator affirms as appropriate and insightful.

Wall Post 35. Jonathan [pseudonym] is quite correct, as long as you have a customer form that captures their info and a submit button. Check pg52-53 of the guide I gave you ...it could help on how to save results in a database.....as well as get results from a database....but i don't expect all functionalities to work....

The transformation in the social practices of students from general information seeking to information giving and advising is a clear reflection of the transformative power of an informing 
driven networked platform. Some students assumed additional roles as knowledge givers, a vertical role that traditionally seemed to be the domain of Informers (experienced experts).

\section{Relevance of Contextual Accuracy and Institutional Memory}

On Facebook, the Informer renders information to other clients in transactional spaces with inbuilt mechanisms for backtracking conversation history, thus presenting some form of organisational memory for both the client and the informer. This technological affordance was put forward by another learner:

With Facebook, I can send a query to my educator from my cell phone and use the Facebook notice board to retrieve the message. Often the list of questions and answers queue and pile up allowing me to access all the queries asked by peers. If I have airtime, I use my mobile phone to communicate, so it is convenient because I need not commute to upper campus [one of the university campuses] to access Facebook. (Debriefing with student)

The facility for tracking back conversations on Facebook was not employed by the majority of students because of time constraints. The educators grumbled about the incidences of repetitive or related questions that constrained their capacity to respond given the volume of questions raised. The transformative nature of one of the educators' practice is embodied in her postulation of future pedagogical interventions:

Students often do not bother checking the list of questions addressed to ascertain whether their query has been addressed before asking me on Facebook and this complicate my responsibility of addressing their queries. I think that in future we will need to put in Facebook a programme or software for searching frequently asked queries related to what students have asked. Students can type these questions to see if their question has been asked before so as to reduce the number of redundant questions. Facebook is supposed to expedite learning by clearing out dross. (Educator debriefing)

The transformation of the educator's pedagogical practices is embodied in the innovative proposition of the frequently asked questions tool on Facebook to expedite the Client's information search and save her time through elimination of extraneous questions. This shows the nuanced intersection of the informing environment of the Client and Informer through the informing channel. The other unintentional practice that also triggered redundancies was shy students' use of private spaces (Facebook inbox) to communicate queries thus depriving the inquiring and informing community of access to questions already addressed. Transformative practices manifested in the educator admonishing students to refrain from communicating via her private inbox and to deploy public communication spaces (wall and discussion) that were publicly accessible to all learners.

\section{Challenges of Off-Domain Questions}

Students often asked novel questions that transcended the domain of the online administrator who addressed them. Mindful of the huge undergraduate classes at this university and diverse educators who taught different aspects of the IT course, the Informer's (online administrator) challenge was to tackle questions that lay outside her teaching /research domain (subject-role dilemma). She remarked that:

Students often ask random questions that fall outside my teaching load. So because I handle all Facebook as a learning tool, I should address this even though I did not teach this concept and this is a challenge. We have approximately 850 students and so we have 5 educators teaching the same course. When an educator teaches chapter 12 which I 
don't know or I haven't read about, and all I know is that it is part of the syllabus and a student posts a question, so I have to do additional work. (Educator debriefing)

The educator's cognitive fragility was apparent when her scope of responsibilities (roles) was expanded and was expected to conduct additional research to sufficiently address the expanded portfolio. The shift in the object to embrace a radically expanded activity system was verbalized in her expectations about collaborative engagement with her colleagues to support her Facebook role:

We need to have sub-groups dealing with different aspects on Facebook like practicals, exams, conceptual issues, which is more difficult because educators do not have time. Some form of specialisation would be necessary for Facebook to be more academically meaningful to students. The workload is more on my side because if someone asked a question I didn't teach, I will have to go and see what that educator taught first before replying to that student. (Educator debriefing)

While this main educator was highly competent to address the majority of queries students raised, some questions demanded her understanding of the situated contexts in which they arose without which responses would be counterproductive. Her consciousness of the need for collaborative interaction with her peer academics and her consultative process thereof could be interpreted as forms of pedagogical transformation involving expanded scope of activity systems that instigated new dynamic interplays of inconceivable interactions. This demonstrates the complexity of strategically aligning and integrating a complementary informing space with mainstream teaching and learning as effective co-ordination of research and teaching mandates across the department's staff is necessary.

\section{An Information Sharing Pedagogical Framework}

In a heterogeneous informing system, Facebook, the object of relations between Clients and Informers was driven by a host of variables, which were not always apparent to Clients. The objects did not necessarily have to be academic, for instance, the aesthetic considerations of Facebook (social presence of the informer, affective and sentimental value of Facebook) and the technical architecture of the informing channel (synchronicity, quick communication). These ancillary objects of Facebook compounded by the Internet generation's desire for instant communication were not directly congruent with the exclusively academic objects sought by the Informers. The aforementioned misalignment of intentions necessitates an Information Sharing Pedagogy that is inclusive but unitary in perspective. Knowledge sharing is a central aspect of the knowledgebased theory of an organisation because the primary reason for the existence of an organisation is its superior ability to transfer and integrate multiple knowledge streams and to apply existing knowledge to tasks (Grant, 1996; Ryan, Windsor, Ibragimova, \& Prybutok, 2010). As such, an Information Sharing Pedagogy that embraces diverse social exchanges among Clients but is deeply anchored in academic informing and in which pedagogical objects of this informing system are apparent to Clients is necessary. To accomplish this, a mission statement on the Facebook group home page that spells out in details the educators' goals and expectations of students on Facebook could be necessary to compliment the educators' reinforcement of academic networking in lectures. Although, this predisposes students to academic informing at the expense of other forms of interaction, this could recruit and focus students' cognitive schemas towards academic tasks and objects on the informing system. Clients' sense of ownership is retained by the few instances of playful interaction permitted in the informing channel. The Informers should also clarify on the home page of the Facebook group the roles and obligations of educators and students as well as ground rules for appropriate behaviour. This would encapsulate a categorical description of what educator-student 'friendship' means on Facebook to eliminate misinterpretations that may arise concerning the use of the term 'friends.' 
More so, although some students were enthusiastic about Facebook use, they were not technophiles who could effectively use all Facebook spaces and applications for academic networking, information generation, and exchange. This has implications for instructional designers as they need to align the motivations of the Information Sharing Pedagogy, the tool-in-use, and student conceptions of learning using the tool. Re-skilling of students and re-orientation of their learning objects, learning needs, and priorities in tandem with pedagogical intentions of the educators would improve pedagogical delivery. This re-orientation should not only target clients but should be universal. An Information Sharing Pedagogy that augments academic networking through the involvement of previously non-participating groups, such as tutors, could be useful. Tutors could work as 'umpires' who moderate Facebook tutorial groups to enhance the informing potential of this channel. They could set collaborative informing tasks, such as collaborative IT projects, group assignments like book reviews, and critiques of recommended readings, thus empowering Clients to inform other Clients. This liberates the informing channel from being a transmission channel to an informing network.

From an informing channel perspective, social capital established in knowledge workers' social networks enables them to be better informed - to be exposed to valuable job-related information (Burton, $\mathrm{Wu}, \&$ Prybutok, 2010). In the same vein, if academics and students were to be constructed as knowledge workers innovatively building knowledge networks, Facebook would constitute an informing channel through which students accessed task-related knowledge and theoretical information from clients (knowledgeable peers, educators). The anonymity afforded by Facebook inboxes and presumptuous anonymity ingrained in Facebook public spaces permit shy clients to protect their self image when confessing sheer ignorance or slow learning. Rather than discourage Informer-Client private communication (via Facebook inboxes), tutors could use this private informing channel to train and socialise students in academic-related matters (e.g., making administrative queries), allowing for progression to critical questioning on theoretical issues. This Information Sharing Pedagogy would train students to post logical queries and familiarise them with private debates as precursors to public engagement as critical questioning skills are mastered. More so, this user-friendly ambience renders informing possible through presentation of queries, which would not otherwise be raised in educators due to perceived psycho-social, cognitive, and semiotic fragilities like feelings of alienation, limited self-confidence, and constrained linguistic competence.

The challenge of the Facebook informing channel (private inbox) on the one hand was its violation of the networked effect envisioned by the academic authorities. The prescription offered by academics to publicize all social networked interactions unintentionally subverted the information seeking behaviour of these shy clients, on the other. The pedagogical lesson learnt is that when academics encroach informal learning spaces to shift behavioral practices of clients, the conceptions of learning should be transformed from seeing learning as solely involving cognitive shifts towards perceiving it as embedded in social relations. These difficulties of online learning resonate with Kirkwood's (2009) evidence of the failure of technology-led innovations within higher education (HE) in Western contexts to achieve the anticipated transformations in learning and teaching. He attributes this failure to the differences in students' expectations and understandings of "learning" (likewise their educators) and "assessment" - that is, students are more instrumental and assessment-driven in their online learning behaviour because of the calls on their time due to work and domestic responsibilities (cited in Lukaitis \& Davey, 2010).

From a Connectivist point of view, Calvani (2008) suggests:

Learning is considered a continuous process mainly residing in non human applications, that is in technologies and connections between knots: among the main agents are difference of opinion, ability of seeing connections between fields, ideas and concepts (transvergence), suspension of certainty. (p. 248) 
These knowledge workers (Clients and Informers) should be able to advance meaningful relations that generate new understandings (transformations) while managing the complexities that come with the violation clients' established practices (for example, choice of communication channel).

Engeström (2001) presents multi-voicedness and dialogicality as the forces for transformation of the object and the social practices as new diverse, conflictual positions present opportunities for change. The concept of "mass intellectuality" (Virno, 1996) embraced in Facebook informing process demands Informers (educators) to understand and diagnose clients' (students) levels of understanding and to provide a strategy for cultivating academic discourses through deliberately orchestrated tasks and knowledge sharing practices that feed into mainstream learning. The challenge discerned in this work is how academics could activate this in a space conceivably regulated by students and where participation is based on individual Clients' volition. For academically inclined students, however, Facebook relations presented "benefits that accrue to the collectivity as a result of the maintenance of positive relations between different groups, organizational units, or hierarchical levels" (Kilduff \& Tsai, 2003, p. 26). The challenge was to tap on this potential without necessarily losing the socialising element, which students often prized, or allowing it to recede in the background given that the entertainment facet carried sentimental value to the majority of them.

Informing at the organization level unravels some of the taken-for-granted assumptions that drive computer mediated interaction, particularly the unsubstantiated view that students are a homogeneous body whose academic empowerment needs can be meet trouble-free through computer mediated engagement (Facebook). To the contrary, the general apathy of students on Facebook demonstrates the replication of disadvantage online as less confident and unsophisticated Clients (learners) could have failed to gain leverage in these spaces. The low participation rates can also be interpreted as students' lack of motivation to learn and their orientation towards shallow learning where the need to secure a qualification overrides criticality, comprehension, and knowledge generation. This attitude is supposedly heightened by the commodification of higher education and prevalence of plagiarism and cheat sites such as Essaybay. Yet the adoption of vertical roles by a minority mirrors the transformative processes in complex activity systems. Therefore, the negotiation of shared meaning in technology-rich environments is contingent on the capacity of students to embrace, comply with, or even resist innovation as part of the transformation processes in higher education (Carr et al., 2007). More so, the cases deliberated above suggest that technological tools expand our possibility to manipulate and transform objects but also restrict our accomplishments within the limitation of the tool, which, in turn, often stimulates improvements to the tool (Verenikina \& Gould, 1998).

From an organisational perspective, challenges of collaborative engagement were apparent as some academics were challenged to co-operate with the online administrator amid other competing administrative and academic commitments. This fails to reinforce the claim made by literature that participatory culture shifts the focus of literacy from individual expression to community involvement through collaboration and networking (Jenkins, Clinton, Purushotma, Robison, \& Weigel, 2006). The online administrator was challenged to access the much need support from her academic colleagues as she was smothered by the workload.

From an informing science perspective, the sophisticated students' claim that peers' posting rendered them some mental modelling and self- assessment as they employed them as lens for gauging personal understanding was academically insightful. This understanding predisposed students to take a transdisciplinary approach to information generation where they could glean beyond their discipline for other Informers (knowledgeable peers, senior students, academics, extended academic community in other related fields) to transact information. From a technical perspective, the quasi-formal, fluid, and muddled nature of this informing system affords free flow of information tied to a network of temporal social ties, and exploratory learning guided by trial and 
error, less palatable in mainstream learning. The transdisciplinary nature of Facebook informing process affirms Crawford and Hasan's (2006) vision of a tool that shapes activities in different ways as the objects (purposes) of users are diverse, both within and between groups, and within each work activity. In addition, each person in a socio-technical system brings a unique cultural history, personality, and knowledge base and thus interprets, makes sense of, and responds to the system individually (Crawford \& Hasan, 2006). Clients' diverse interpretations of the object of Facebook well resonate with the aforementioned authors' observations. Academic authorities are, therefore, under pressure to evolve pedagogical approaches that capture the complexity and transdisciplinary nature of knowledge production, abrogating the canons of disciplinary focus that frame mainstream learning.

The subversion of comfort zones highlighted by some students in Facebook is an issue of the design of human-computer interaction. Academics need to recognize the tradeoff between collective generation of knowledge and the students' perceived fear of loss of control that accompanies academic presence on social media. As Sharples, Taylor and Vavoula (2005) suggest, control may also pass between learners and technology in a dialogue for computer-based instruction, and technological benefit derives from whether learners can access materials when convenient and whether they can control the pace and style of interaction. In our case, the advantage was the possibilities for accessing and generating transdisciplinary knowledge, with a perceived undercut on Clients rights to self-regulation in knowledge production and personal privacy as academics enter their territory. That said, Facebook control is multi-layered, as manifested by male student capacity to articulate gender performativity. Male students asserted their chauvinist and impressionist identity on their wall posts, though the practice carried a low academic profile.

We are mindful of the tensions between privacy emphasised by novices and their desire to be informed through a collaborative informing system. Because the Facebook informing network is created through personal invitations, a Client-friendly Information Sharing Pedagogy could encourage learner participation in a discursive community (on Facebook), while at the same time discouraging educators from sending private 'friendship' invitations to individual students. This asymmetrical access would breach social distance between Clients and Informers while assuring students of their privacy if they are ambivalent about educator access to their personal web pages.

Instead of providing background information in problem solving, providing leading questions, or detailed explanations that often unintentionally entrench cycles of student dependence on educators for academic support (Rambe, 2010), a network of independent knowledge workers needs to be fostered. This would involve students working on collaborative IT projects, technical reports, and open literature reviews on Facebook where the lecturer becomes one among a network of Informers (peers, senior students, few academics, peers on remote campus, and international students in other universities). To couple academic projects with Clients' preoccupation with identity construction, IT projects could be modelled around their expression of agency. For example, a project on how individual students' personas are shaped and transformed by their use of social media could be developed.

Lastly, an Information Sharing Pedagogy anchored in deep, reflexive learning demands students training in the use of Facebook as an information repository to allow for quick browsing of appropriate answers and critical reflection. This would increase student germane load on cognitively demanding issues, focus discussions on theoretical issues, and eliminate redundant questions. A frequently asked questions (FAQ tool) software like DFAQ could eliminate dross and low-order questions while directing the informing process towards higher-order questions. Mindful of lecturers' incapacity to answers questions because of huge workloads, this software should be designed to relay off-domain questions to particular tutors who can handle them to reduce information overload on the online administrator. 


\section{Conclusion}

The informer and client framing concepts, as Cohen (2009) espouses, are essential concepts to grasping the informing process on Facebook. The less explicit and undefined nature of Facebook complicated the maintenance of the academic thrust of discussions as some students hijacked the space for impressionist behaviours. The Informer's framing as embodied in the demands for students to communicate publicly for their academic networking benefit was logical, this enframed (i.e., imposed constraints) students who had shied public communication due to their limited confidence in public communication or fear of ridicule by peers for posing unsophisticated questions. The challenge, therefore, was to expand the network of activity systems radically through public participation when their preferred communication channel was blocked. Cohen (2009) suggests that the informing science framework emphasises explicit understanding of the limitations, that is, the "fragility" of the Informer, the channel, and the information Client. The fragilities of the Client manifested in some students' negative perceptions towards the informing channel as it came across as a 'tool of enforcing discipline' as their preferred information channel was overruled. This finding supports the view that organisations that successfully deploy information technology (IT) to support knowledge sharing affirm that technology alone is not sufficient to produce the desired results (Ryan et al., 2010) as organizational practices and policies are equally critical in knowledge sharing efforts (Brazelton \& Gorry, 2003).

It should, however, be stressed that the topic-based and peer-initiated nature of the conversations on the Facebook Wall and Discussion Board ensured a systematic articulation of issues in a manner that allowed even the less confident, academically oriented students to follow or to lurk around for a short while to experience/track the flow of the discussion and to acquire through observation the communicative genres needed before joining in these discussions. Unintentionally, as time progressed, this interaction allowed such students to discern that they were not the only ones with comprehension problems and, therefore, triggered their improved participation. Because all the students were first years doing the same course, this reinforced a sense of a cohesive, discursive community that could be potentially self-sustaining with persistent interaction and the building of trust. Instructional designers should develop informing channels that strike a legitimate balance between demands for academic networking and the protection of identity, and the safeguarding of the learning interests and expectations of less confident, academically challenged learners.

Multiple dialogues on the academic value of Facebook serve as evidence for clients' diverse socio-cultural and historical context shaping their varied, complex views on this informing channel. Students' historicity which ranged from diverse prior exposure and experiences with Facebook use, different forms of prior uses of Facebook, extent of off campus use, and historical disadvantages all frame perceptions of potential and actual use. Some students who were already socially networking on Facebook before educator appropriation of the site for academic purposes resisted its academic usage. Yet others, who embraced academic use as an innovative application, expanded the scope of its use, acquiring radically expanded roles. This is congruent with Engeström's (2001) view of expansive transformation as encapsulating the reconceptualisation of the object and motive of activity to embrace a radically wider horizon of possibilities than in the previous mode of the activity. The diversity in Client' perceptions of Facebook mirror Cohen's (2009) revised informing models, which acknowledges that the client, just like the transmission process and informer, exist within complex environments that greatly impact them. The resisting of Facebook use for perceived fear of administrative surveillance, Clients' cognitive limitations to employ it in academically meaningful ways, and limited communicative and ICT competence all point to the entity's (Client) own psychological and physiological fragilities and unmet anticipations, which exist within and are influenced by environmental context. 


\section{Implications}

The incidences of redundant questions from clients not only manifest the failure of many Clients to use the Facebook informing system as an information repository (that is, browsing and tracking of the conversational history for questions already addressed) but their incapacity to understand the functionality of the transmission channel (medium). The Informer, therefore, should not assume that learners have the learning strategies and [networking] skills at the beginning of the learning process, nor are all learners prepared for self-instruction (Tan \& Chan, 1997). As such, clients need to be apprised, not only about how to access the information via the informing channel (medium), but also the ground rules for engagement and the functionality of the medium itself. This supports Tversky and Kahneman's (1981) view that the behaviour of the "Client" depends not only on the information transferred from the Informer, but also on the context, or frame, in which the information is transferred.

The principal informer was overwhelmed by the manifold of questions that limited her ability to address them without the support of colleagues who co-taught the course. The above demonstrates the limitations of the instrumentalist approach to technology where more emphasis tends to be put on technological affordances at the expense of the other contextual factors like collaborative support and cyberthreats (like cognitive load) that accompany use of the informing environments. For example, the informer's fragility, that is, "cognitive limitations of human processing of information" (Cohen, 2009, p. 8) was apparent when extraneous questions inundated her. An informing framework with mechanisms for showing the incidences of frequently asked questions, their responses, and unanswered questions could be necessary in Facebook to reduce the cognitive demands on the Informers.

The transdisciplinary nature of Facebook consultations manifested in the need for the cooperation of faculty staff to meaningfully support students, without whom the Informers' support would be insufficient. This understanding finds backing in Wilson's (1981) model that emphasises that information needs of individual Clients are complex and are a function of context, environment, social or job role or task, and the individual's psychology (cited in Cohen, 2009). The complexity of the Clients' needs was apparent in the requirement for the Informer not only to apply her mental frames in addressing the questions posed (the task at hand) but also in understanding the circumstances and the context under which these questions arose. This was necessary if the responses were to be intelligible. The above demonstrates the challenges of collaborative group processes among departmental staff that potentially impedes new transformative activity systems. In Engeström's (2001) terms, transformation arises as the contradictions of an activity system are aggravated, escalating into collaborative envisioning and a deliberate collective change effort. In the educators' case, although collaborative action was sought it was not well rendered by peers, signifying the constraints of innovation in an over-burdened informing system.

\section{References}

Bakhtin, M. M. (1986). Speech genres and other late essays. Austin: University of Texas Press.

Barab, S. A., Barnett, M., Yamagata-Lynch, L., Squire, K., \& Keating, T. (2002). Using activity theory to understand the systemic tensions characterizing a technology rich introductory Astronomy course. Mind, Culture, and Activity, 9(2), 76-107.

Barab, S., Hay, K., \& Yamagata-Lynch, L. (2001). Constructing networks of action- relevant episodes: An in situ research methodology. The Journal of the Learning Sciences, 10(1\&2), 63-112.

Bernstein, B. (2000). Pedagogy, symbolic control and identity: Theory research critique (Revised ed.). Oxford: Rowman and Littlefield. 
Birdsall, F. W. (2009). The role of the client in informing science: To be informed and to inform. Informing Science: The International Journal of an Emerging Transdiscipline. 12, 147-157. Retrieved from http://www.inform.nu/Articles/Vol12/ISJv12p147-157Birdsall535.pdf

Bishop-Russell, J., Dubord, M., Hansen, E., \& Webster, K. (2006). Acknowledging campus.com(munity): [TheFacebook] and diversity college. University of Maine. Retrieved January 12, 2009, from www.studentaffairs.com/vcs/2006entries/UniversityofMaine.ppt

Boyd, D. (2007). Social network sites: Public, private, or what? Knowledge Tree, 13. Retrieved June 13, 2010, from http://kt.flexiblelearning.net.au/tkt2007/?page id=28

Brazelton, J., \& Gorry, G. A. (2003). Creating a knowledge-sharing community: If you build it, will they come? Communications of the ACM, 46(2), 23-25.

Burton, P., Wu, Y., \& Prybutok, V. (2010). Social network position and its relationship to performance of IT professionals. Informing Science: The International Journal of an Emerging Transdiscipline, 13, 121-137. Retrieved from http://www.inform.nu/Articles/Vol13/ISJv13p121-137Burton554.pdf

Calvani, A. (2008). Connectivism: New paradigm or fascinating pot-pourri? Journal of e-Learning and Knowledge Society, 4(1), 247-252.

Carr, T., Morrison, A., Cox, G., \& Deacon, A. (2007). Weathering wikis: Net-based learning meets political science in a South African university. Computers and Composition, 24, 266-284.

Cartelli, A., Miglio, L., \& Palma, M. (2001). New technologies and new paradigms in historical research. Information Science, 4(2), 61-66.

Charnigo, L., \& Barnett-Ellis, P. (2007). Checking out Facebook.com: The impact of a digital trend on academic libraries. Information Technology and Libraries, 23-34.

Cohen, E. B. (2009). A philosophy of informing science. Informing Science: The International Journal of an Emerging Transdiscipline, 12, 1-15. Retrieved from http://www.inform.nu/Articles/Vol12/ISJv12p001-015Cohen399.pdf

Cohen, E. B., \& Nycz, M. (2006). Learning objects and e-learning: An informing science perspective. Interdisciplinary Journal of E-Learning and Learning Objects, 2, 23-34. Retrieved July 27, 2009, from http://www.ijello.org/Volume2/v2p023-034Cohen32.pdf

Crawford, K., \& Hasan, H, (2006). Demonstrations of the activity theory framework for researching IS. Australasian Journal of Information Systems, 13(2), 49-68.

Daniels, H. (n.d.). Studying shifts in subject position from the perspective of activity theory. The Centre for Sociocultural and Activity Theory Research. Retrieved May 07, 2009, from http://orgs.man.ac.uk/projects/include/experiment/harry_daniels.pdf

DiMicco, J. M., \& Millen, D. R. (2007). Identity management: Multiple presentations of self in Facebook. GROUP'07, Sanibel Island, Florida, USA, November 4-7.

Ellison, N. B., Steinfield, C., \& Lampe, C. (2007). The benefits of Facebook friends: Social capital and college students' use of online social network sites. Journal of Computer Mediated Communication, 12(4). Retrieved October 17, 2009, from http://jcmc.indiana.edu/vol12/issue4/ellison.html

Engeström, Y. (1987). Learning by expanding: An activity-theoretical approach to developmental research. Helsinki: Orienta-Kosultit Oy, Finland.

Engeström, Y. (1992). Interactive expertise studies in distributed working intelligence. Helsinki: University of Helsinki.

Engeström, Y. (1995). Objects, contradictions and collaboration in medical cognition: An activitytheoretical perspective. Artificial Intelligence in Medicine, 7(5), 395-412.

Engeström, Y. (1999). Innovative learning in work teams: Analysing knowledge creation in practice. In Y. Engeström, R. Miettinen, \& R-L Punamaki (Eds.), Perspectives on activity theory: Learning in doing social, cognitive and computational perspectives (pp. 377-404). UK: Cambridge University Press. 
Engeström, Y. (2000). Activity theory as a framework for analyzing and redesigning work. Ergonomics, 43(7), 960-974.

Engeström, Y. (2001). Expansive learning at work: Toward an activity theoretical reconceptualisation. Journal of Education and Work, 14(1), 133-156.

Gender performativity. (n.d.). In Wikipedia. Retrieved April 28, 2011 from http://en.wikipedia.org/wiki/Gender_performativity

Granott, N. (2005). Scaffolding dynamically toward change: Previous and new perspectives. New Ideas in Psychology, 23, 140-151.

Grant, R. M. (1996). Toward a knowledge-based theory of the firm. Strategic Management Journal, 17, 109-122.

Grude, A., Scholl, M., \& Thompson, R. (2006). Privacy on facebook. Computer Supported Cooperative Work, SI689, 1-17.

Hasu, M., \& Engeström, Y. (2000). Measurement in action: An activity-theoretical perspective on producer-user interaction. International Journal of Human-Computer Studies, 53, 61-89.

Hendry, J. (1998). The analysis and prediction of student progression through degree programmes: A cohort analysis of undergraduate students at the University of Cape Town. Unpublished master's thesis, University of Cape Town, South Africa.

Hewitt, A. \& Forte, A. (2006). Crossing boundaries: Identity management and student/faculty relationships on the facebook. $C S C W^{\prime} 06$, Banff, Alberta, Canada, 1-2.

Jenkins, H., Clinton, K., Purushotma, R., Robison, A., \& Weigel, M. (2006). Confronting the challenges of participatory culture: Media education for the 21st century. The John D. and Catherine T. MacArthur Foundation. Retrieved May 22, 2009, from http://digitallearning.macfound.org/atf/cf/\%7B7E45C7E0A3E0-4B89-AC9C-E807E1B0AE4E\%7D/JENKINS WHITE_PAPER.PDF

Kaptilinin, V. (1996). Computer-mediated activity: Functional organs in social and developmental contexts. In B. A. Nardi (Ed.), Context and consciousness: Activity theory and human computer interaction (pp. 45-68). Cambridge, MA: MIT Press.

Kilduff, M., \& Tsai, W. (2003). Social networks and organizations. Thousand Oaks, CA: Sage Publications.

Kirkwood, A. (2009). E-learning: You don't always get what you hope for. Technology, Pedagogy and Education, 18(2), 107-121.

Koszalka, T. (2002). A cultural historical activity theory (CHAT) analysis of technology Integration: Case study of two teachers. AERA 2004, 492-502. San Diego, CA. Retrieved May 13, 2007, from http://soeweb.syr.edu/ takoszal/electronic_portfolio/scholarship/AERA2004_Koszalka_Wu.pdf

Laboratory of Comparative Human Cognition. (In Press). Qualitative research: Cultural-historical activity theory. In B. McGaw, P. Peterson, \& E. Baker (Eds.), International Encyclopedia of Education (pp. 113). New York: Elsevier.

Leontiev, A. N. (1978). Activity, consciousness, and personality. Englewood Cliffs, NJ: Prentice-Hall.

Lukaitis, A. \& Davey, B. (2010). Motivations of the online student. Issues in Informing Science and Information Technology, 7, 25-39. Retrieved from http://iisit.org/Vol7/IISITv7p025-039Lukaitis782.pdf

Madge, C., Meek, J., Wellens, J. \& Hooley, T. (2009). Facebook, social integration and informal learning at University: It is more for socialising and talking to friends about work than for actually doing work. Learning, Media and Technology, 34(2), 141-155.

Matos, J., \& dos Santos, M. (2008). Activity, artefacts and power: Contribution of activity theory and situated learning to the analysis of artefacts in mathematical thinking in practice. In J. F. Matos, P. Valero, \& K. Yasukawa (Eds.), Proceedings of the Fifth International Mathematics Education and Society 
Conference (pp. 1-12) Lisbon: Centro de Investigação em Educação, Universidade de Lisboa - Department of Education, Learning and Philosophy, Aalborg University.

McIntyre, S. (2008). Leap of faith: Effective steps for establishing online collaborative learning initiatives. Proceedings of the $3^{\text {rd }}$ International Conference on E-learning (pp. 283-292). Reading, UK: Academic Publishing.

McLean, M. (2004). Is culture important in the choice of role models? Experiences from a culturally diverse medical school. Medical Teacher, 26,142 - 149.

McMillan, W. J. (2007). Understanding diversity as a framework for improving student throughput. Education for Health, 20, 1-6.

Miller, T. W. (2000). Marketing research and the information industry. A. C. Nielsen Center for Marketing Research, University of Wisconsin-Madison School of Business.

Morrison, A. (2004). Artful roles in blended learning: Reflections on collaborative digital arts and Zimbabwe. Emerge Online Conference. Retrieved June 05, 2008, from http://emerge2004.net/connect/site/UploadWSC/emerge2004/file62/Morrimerge.pdf.

Morrow, W. (1994). Entitlement and achievement in education. Studies in Philosophy and Education, 13, 33-37.

Murphy, E., \& Rodriguez-Manzanares, M. A. (2008).Using activity theory and its principle of contradictions to guide research in educational technology. Australasian Journal of Educational Technology, 24(4), 442-457.

Njenga, J. K., \& Fourie, L. C. (2010). The myths about e-learning in higher education. British Journal of Educational Technology. 41(2), 199-212. Retrieved December 13, 2010, from http://onlinelibrary.wiley.com/doi/10.1111/j.1467-8535.2008.00910.x/pdf.

Petersen, I., Louw, J., \& Dumont , K. (2009). Adjustment to university and academic performance among disadvantaged students in South Africa. Educational Psychology, 29(1), 99-115.

Qualitative Research: (Critical) Ethnography Guidelines. (n.d.).TESOL Quarterly. Retrieved May 17, 2010, from http://www.tesol.org/s tesol/sec document.asp?CID=476\&DID=2157

Rambe, P. (2009). The impact of using social networking sites on academic relations and student learning in university setting. PhD Thesis, University of Cape Town, Cape Town.

Rambe, P. (2010). Using contradictions to ravel teaching and learning challenges in a blended IS course in an African University. Journal of Information, Information Technology, and Organizations, 5, 101124. Retrieved from http://www.jiito.org/articles/JIITOv5p101-124Rambe461.pdf

Rambe, P., \& Ng'ambi, D. (2008). Barriers to students' use of electronic resources during lectures. Conference paper presented at the Sacla Conference, July 13-16, 2008.

Rasmussen, T. (1996). Communication technologies and the mediation of social life. University of Oslo, Department of Media and Communication. IMK-report no. 16.

Republic of South Africa (1997). Education White Paper 3 - A programme for higher education transformation. Government Gazette, 4 no. 18207, August 15, 1997.

Roth, W., \& Lee, Y. (2004). Interpreting unfamiliar graphs: A generative, activity theoretic model. Educational Studies in Mathematics, 57(2), 265-290.

Russell, D. L., \& Schneiderheinze, A. (2005). Understanding innovation in education using activity theory. Educational Technology and Society, 8(1), 38-53.

Ryan, S. Windsor, J., Ibragimova, B., \& Prybutok, V. (2010). Organizational practices that foster knowledge sharing: Validation across distinct national cultures Informing Science: The International Journal of an Emerging Transdiscipline, 13, 139-164. Retrieved from http://www.inform.nu/Articles/Vol13/ISJv13p139-164Ryan540.pdf 
Selwyn, N. (2007). Web 2.0 applications as alternative environments for informal learning - A critical review: Using ICT to change impact and outcomes. A paper prepared for OECD-KERIS expert meetingsession-alternative learning environments in practice (pp. 1-10). Institute of Education, University of London.

Sharples, M., Taylor, J., \& Vavoula, G. (2005). Towards a theory of mobile learning. In H. van der Merwe \& T. Brown (Eds.), Mobile technology: The future of learning in your hands (pp-1-9), mLearn 2005, 4th World Conference on mLearning, Cape Town, 25-28 October 2005. Available online at http://www.mlearn.org.za/CD/papers/Sharples-\%20Theory\%20of\%20Mobile.pdf

Siemens, G., \& Tittenberger, P. (2009). Handbook of emerging technologies for learning. University of Manitoba.

Tan, F. B. \& Chan, H. (1997). Managing self-instructed learning within the IS curriculum: Teaching learners to learn. Informing Science: The International Journal of an Emerging Transdiscipline, 1(1), 1-7. Retrieved from http://www.inform.nu/Articles/Vol1/v1n1p1-7.pdf

Tversky, A., \& Kahneman, D. (1981). The framing of decisions and the psychology of choice. Science, $211(4481), 453-458$.

Uden, L., \& Kumaresan, A. (2007). Usable collaborative email requirements using activity theory. Informatica, 31, 71-83.

Van der Merwe, A. \& Mouton, J. (2005). Integrating ICTs into the teaching and learning environment: An investigation of educator perceptions of possible barriers and incentives. Perspectives in Education, 23(4), 19-37.

Verenikina, I. \& Gould, E. (1998). Cultural-historical psychology and activity theory. In H. Hasan, E. Gould, \& P. Hyland (Eds.), Information systems and activity theory: Tools in context (pp. 1-18). Wollongong University Press.

Virno, P. (1996). Notes on the general intellect. In S. Makdisi, C. Casarino, \& R. E. Karl, (Eds.). Marxism beyond Marxism (pp. 265-272). London: Routledge.

Vygotsky, L. (1978). Mind in society: The development of higher psychological processes. Cambridge, MA: Harvard University Press.

Wertsch, J., del Rio, P., \& Alvarez, A. (1995). Sociocultural studies: History, action, and mediation. In J. V. Wertsch, P. del Rio, \& A. Alvarez (Eds.), Sociocultural studies of mind (pp. 1-34). New York: Cambridge University Press.

Wilson, T. D. (1981). On user studies and information needs. Journal of Documentation, 37(1), 3-15.

Zurita, G. \& Nussbaum, M. (2007). A conceptual framework based on Activity Theory for mobile CSCL. British Journal of Educational Technology, 38(2), 211-235. 


\section{Biographies}

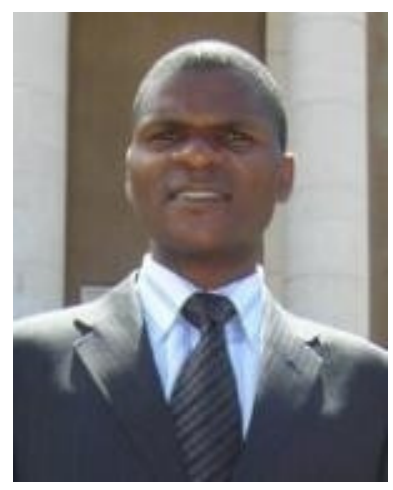

Patient Rambe holds a PhD in Educational Technology from the University of Cape Town, South Africa. His research interest is the innovative pedagogical use of Social Media and other Web-based technologies in resource-constrained environments. His doctoral research investigated use of Facebook at a higher education institution in a South African context.

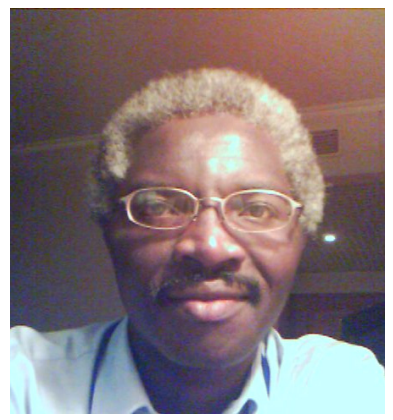

Dick Ng'ambi, $\mathrm{PhD}$ is an Associate Professor in the Centre for Educational Technology at the University of Cape Town and head of a Postgraduate Programme in Education (Information and Communication Technologies Stream). He is a leading researcher in mobile learning in developing contexts. His research interests are driven by his quest to exploit low-cost technologies to empower silenced and marginalized voices to become co-producers of knowledge. His research is widely circulated and rated by the National Research Foundation (NRF). 